\title{
La guerra de los Estados Unidos contra la inmigración. Efectos paradójicos*
}

\author{
Douglas S. Massey \\ Karen A. Pren \\ Princeton University. Office of Population Research \\ dmassey@princeton.edu \\ kapren@princeton.edu
}

Recepción: abril de 2012

Aceptación: noviembre de 2012

\section{Resumen}

A finales de la década de 1950, Estados Unidos permitía la entrada de aproximadamente medio millón de inmigrantes mexicanos al año, de los cuales 450.000 llegaban con visados de trabajo temporal y 50.000 lo hacían con visados de residentes permanentes. A mediados de la década de 1960, los cambios en la política migratoria de Estados Unidos realizados en nombre de los derechos civiles redujeron drásticamente las oportunidades de entrada legal en el país. Se eliminaron los visados de trabajo temporal y se limitaron los visados de residentes a 20.000 por año. Con las oportunidades de entrada legal restringidas, los flujos migratorios ya establecidos simplemente continuaron fuera de los límites legales, lo cual dio comienzo a una inesperada reacción en cadena de eventos que culminaron en una guerra total contra los inmigrantes y el rápido crecimiento — sin precedentes - de población residente no autorizada en Estados Unidos. El presente artículo demuestra que el aumento de inmigración indocumentada en los Estados Unidos y el incremento de la población sin papeles son un producto de políticas migratorias y fronterizas mal concebidas.

Palabras clave: inmigración indocumentada; México; Estados Unidos; política migratoria; visados temporales; visados permanentes.

\section{Resum. La guerra dels Estats Units contra la immigració. Efectes paradoxals}

A finals de la dècada de 1950, els Estats Units permetien l'entrada d'aproximadament mig milió d'immigrants mexicans l'any, dels quals 450.000 hi arribaven amb visats de treball temporal i 50.000 ho feien amb visats de residents permanents. A mitjan anys seixanta, els canvis en la política migratòria dels Estats Units realitzats en nom dels drets civils van reduir dràsticament les oportunitats d'entrada legal al país. Es van eliminar els visats de treball temporal i es van limitar els visats de residents a 20.000 per any. Amb les oportunitats d'entrada legal restringides, els fluxos migratoris ja establerts simplement van continuar fora dels límits legals, la qual cosa va donar lloc a una inesperada reacció en

* Revisión del original a cargo de Miguel Solana. 
cadena d'esdeveniments que van culminar en una guerra total contra les persones immigrants i el creixement ràpid — sense precedents_- de població resident no autoritzada als Estats Units. El present article demostra que l'augment d'immigració indocumentada als Estats Units i l'increment de població sense papers són un producte de polítiques migratòries i frontereres mal concebudes.

Paraules clau: immigració indocumentada; Mèxic; Estats Units; política migratòria; visats temporals; visats permanents.

Résumé. La guerre des États-Unis contre la immigration. Effets paradoxaux

Dans la fin des années cinquante, les États-Unis ont autorisé l'entrée d'environ un demi-million d'immigrants mexicains par an, dont 450.000 sont venus avec des visas de travail temporaires et 50.000 sont arrivés avec des visas de résident permanent. À la moitié des années soixante, les changements des politiques d'immigration aux États Unis faits au nom des droits civils, ont réduit considérablement les possibilités d'entrée légale aux États-Unis. Les visas de travail temporaire ont été supprimés et les visas de travail permanent ont été limités à 20.000 habitants par an. Avec les possibilités réduites d'entrée légale, la migration a continué en dehors des limites légales. En conséquence, se produit une réaction en chaîne d'événements inattendus, qui a conduit à une guerre totale contre les immigrés et à la croissance rapide des records de population résidente non autorisé aux États-Unis. Cet article démontre que l'immigration illégale accrue aux États-Unis et la croissance de la population sans-papiers est un produit des politiques d'immigration et des frontières mal conçues.

Mots clé: immigration clandestine; Mexique; politique d'immigration États Unis; visas temporaires; visas permanents.

\section{Abstract. The United States war against immigration: Paradoxical effects}

At the end of the 1950s, the United States permitted the entry of a half million Mexican migrants per year, of which 450,000 entered with temporary work visas and 50,000 as permanent residents. By the mid-1970s, however, changes in U.S. migration policy undertaken in the name of civil rights had eliminated temporary work visas and limited legal resident visas to 20,000 per year. With the opportunities for legal entry curtailed, migratory flows simply re-established themselves under undocumented auspices, giving rise to a chain reaction that culminated in a new war on immigrants and the unprecedented growth of the unauthorized population of the United States. This article shows that the rise of undocumented migration and the growth of America's undocumented population are a product of poorly conceived immigration and border policies.

Keywords: undocumented migration; Mexico; United States; migratory policy; temporary visas; permanent visas.

\section{Sumario}

Los efectos paradójicos de las reformas en los derechos civiles

El surgimiento de la narrativa de la amenaza latina

Efectos sobre la opinión pública
Efectos sobre las políticas públicas Efecto de la guerra contra el terror

La extraña carrera de la guerra contra los inmigrantes

Referencias bibliográficas 
Con frecuencia, la política migratoria de Estados Unidos tiene poco que ver con tendencias y patrones de inmigración, por paradójico que parezca. Si bien las políticas responden, de manera explícita, a cambios en la inmigración, rara vez están cimentadas en correspondencia real con las fuerzas que gobiernan la migración internacional. No hay duda que, a lo largo del tiempo, las restricciones relativas de las políticas de inmigración de Estados Unidos han estado influenciadas fuertemente por las circunstancias predominantes, tanto en lo económico como en lo ideológico (Timmer y Williamson, 1998; Massey, 1999; Meyers, 2004). Los inmigrantes, en especial en Estados Unidos, llevan a cuestas un peso simbólico y significativo en la narrativa del pueblo americano (Smith, 1997, 2003), y su imagen en los medios de comunicación, el retrato divulgado por los políticos y el trato en la legislación más bien ponen al descubierto las aspiraciones y las esperanzas de Estados Unidos - así como sus miedos e inseguridades- que lo relacionan con la inmigración como tal (Tichenor, 2002; Ngai, 2003).

Las actitudes y las políticas en contra de los inmigrantes han sufrido altos y bajos en el curso de la historia de Estados Unidos (Zolberg, 2006). El país se encuentra inmerso en un momento indudablemente xenofóbico que muestra el clima en contra de los inmigrantes no vivido tal vez desde la década de 1920 (Massey y Sánchez, 2010). En una encuesta llevada a cabo en el año 2006, la mitad de los adultos estadounidenses opinaba que «los inmigrantes eran una amenaza para los valores del país» y que «la población debía estar protegida para enfrentarse a la influencia extranjera", mientras que, en el año 2000, únicamente el $38 \%$ de la población pensaba que los inmigrantes eran «una carga para nuestro país». En 2006, pues, este sentimiento se había convertido en opinión mayoritaria (Kohut y Suro, 2006). Bajo estas circunstancias, no fue ninguna sorpresa cuando, en 2010, año en que la legislatura del estado de Arkansas aprobó un paquete de medidas en contra de los inmigrantes, casi el $60 \%$ de la población del país diera su consentimiento a tal medida (López et al., 2011).

El estado de Arizona no es, de ninguna manera, el único estado contrario a la inmigración. Los proyectos de leyes relacionados con inmigrantes presentados en las legislaturas estatales entre 2005 y 2010 se dispararon de 300 a 1.538, y el número de proyectos de ley aprobados ascendieron de 36 a 346 (National Council of State Legislatures, 2011). Al aumento de legislaciones a nivel estatal siguió una expansión previa e impresionante de las medidas de aplicación de la ley migratoria a nivel federal (Massey et al., 2002; Massey y Sánchez, 2010). Por ejemplo, de 1986 a 2009, el número de agentes de la Policía Fronteriza aumentó en 5,5 veces; las horas invertidas en el patrullaje de la frontera, en 8,6 veces; las deportaciones casi alcanzaron el factor 16 , y el presupuesto de la Patrulla Fronteriza aumentó 23 veces (Massey, 2011).

Los inmigrantes percibían con claridad la creciente hostilidad en contra de ellos. El 50\% de las personas inmigrantes de origen latino entrevistadas en 2010 sabían que no eran aceptadas como inmigrantes igual que cinco años antes (López et al., 2010), y los delitos de odio en contra de los hispanos ascendieron un $40 \%$ de 2003 a 2008 , de 426 a 595 en únicamente cuatro 
años (Oficina Federal de Investigaciones de Estados Unidos, 2009). En 2006, el 70\% de los inmigrantes latinos observaba la discriminación en contra de los hispanos como un problema mayor en Estados Unidos; el 68\% estaba preocupado por ser deportado y el 35\% sabía de alguien que ya había sido deportado (Kohut y Suro, 2006). Rosen (1995) se ha referido al surgimiento de las políticas en contra de los inmigrantes que comenzó hacia finales de la década de 1980 como una nueva "guerra contra los inmigrantes».

Este repunte no surgió, desde luego, en un vacío económico y social. Aquí argumentamos que los orígenes de la xenofobia actual pueden rastrearse en las ominosas decisiones tomadas durante la mitad de la década de 1960. Tales decisiones, promulgadas por razones más que elogiables pero desconectadas de cualquier valoración real de sus probables efectos sobre la inmigración, redujeron drásticamente las rutas legales de entrada de latinoamericanos a Estados Unidos en general y de mexicanos en particular. A partir de entonces, los programas de entrada legal de trabajadores temporales, bien establecidos bajo el Programa Bracero (1942-1964), sencillamente los reafirmaba como indocumentados, lo cual dio lugar al aumento de la migración ilegal. Aunque no hubo un crecimiento real del volumen total de entradas desde México, la incursión de la inmigración ilegal en masa ofreció una oportunidad de oro para la burocracia empresarial y para políticos con aspiraciones para presentar la inmigración como una amenaza grave para la nación, y, con ello, movilizar y capitalizar el aumento de ese sentimiento en contra de los inmigrantes para sus propósitos políticos. Dado que los indocumentados eran «ilegales», por definición, eran "criminales» e «infractores», con todas las connotaciones subjetivas y las atribuciones sociales asociadas a tales términos.

Los términos «ilegal» e «indocumentado» prácticamente se han convertido, en la opinión general, en sinónimo de mexicanos y latinos (Lee y Fiske, 2006; Dick, 2011). En la retórica pública y en las declaraciones de los medios de comunicación, se pasan por alto día a día las diferencias entre los migrantes legales y los ilegales. Durante las décadas de 1970 y 1980, los inmigrantes latinos se transformaron en un grupo simbólico y convenientemente utilizado para aumentar el pánico moral de aquellos cuya fuerza política podría ser utilizada para acumular poder y asegurarse recursos administrativos (Chávez, 2001; Massey, 2007; Flores et al., 2011). La construcción de los inmigrantes latinos como amenaza originó el despertar de un electorado y la puesta en marcha de leyes restrictivas a la inmigración y políticas más duras en la frontera, que aumentaron el número de detenciones de inmigrantes y justificaron nuevas restricciones y acciones en la aplicación de la ley migratoria. Estas restricciones dieron pie a más detenciones, que justificaron la necesidad de acciones más rigurosas e impositivas y produjeron un ciclo de retroalimentación que impulsó los esfuerzos por aplicar la ley, a pesar de que el volumen implícito de indocumentados había llegado a su límite más elevado e incluso ya iba en descenso.

Una vez que el ciclo de aplicación de la ley quedó afianzado, una serie de ataques terroristas externos aceleraron la guerra contra los inmigrantes combinándola con la recién declarada "guerra contra el terror», situación que aceleró 
la adopción de medidas en la frontera para aplicar la ley, a la vez que se añadía una nueva dimensión a las imposiciones internas para ello. Dichas imposiciones aumentaron drásticamente la cifra anual de deportaciones. Específicamente, la ley Anti-Terrorism and Effective Death Penalty Act, de 1996, y la ley USA PATRIOT Act, de 2001, impulsaron exponencialmente los ya extendidos esfuerzos por aplicar la legislación a niveles nunca vistos y que aún prevalecen, con consecuencias poderosas pero grandemente desapercibidas sobre las pautas y los procesos de inmigración reinantes.

\section{Los efectos paradójicos de las reformas en los derechos civiles}

Como se hizo notar al comienzo del trabajo, los cambios en las políticas sobre migración en Estados Unidos reflejan, con frecuencia, las esperanzas y las aspiraciones de los estadounidenses, así como sus miedos y sus recelos, sin tener en cuenta las tendencias subyacentes sobre el hecho migratorio. Los miedos y temores de la población que prevalecían en la década de 1920 dieron lugar, sin duda, a la aprobación de una cuota de leyes restrictivas. En respuesta a la creciente desigualdad y a las corrientes predominantes de racismo científico, xenofobia e inseguridad ideológica desatadas por el surgimiento de la Unión Soviética, las Quota Acts de 1921 y 1924 buscaron reducir el número de inmigrantes hacia Estados Unidos y desplazar sus orígenes desde los países del sur y del este de Europa hasta el norte y el oeste europeos, a la vez que se mantenía una prohibición total sobre la inmigración procedente de Asia y África.

Por contraste, las esperanzas y las aspiraciones fueron el Zeitgeist de la década de 1960 que llevó a reformas de liberalización y a una gran apertura. En el contexto del incipiente movimiento de derechos civiles, las cuotas discriminatorias, las prohibiciones a la entrada de negros y la entrada de asiáticos eran vistas como intolerancia racista, razón por la cual fueron derogadas por el congreso en 1965. Además, a mediados de los años sesenta, el Congreso eliminó el Programa Bracero, considerado como un régimen de explotación laboral que contaba con el apoyo de los aparceros del sur, con las furiosas objeciones de México (Calavita, 1992; Massey et al., 2002).

Ambas acciones fueron percibidas en su momento como reformas a los derechos civiles y no como cambios de las políticas migratorias. Estados Unidos se acercaba, en 1965, al final del «largo paréntesis» relacionado con la inmigración (Massey, 1995). De hecho, como eran pocos inmigrantes que se asentaban en Estados Unidos, el porcentaje de nacimientos de población nacida en el extranjero bajó en 1970 a menos del 5\% por primera y única vez en la historia del país. Como resultado, la inmigración no fue un asunto importante en 1965 $\mathrm{y}$, en consecuencia, no se prestó atención a la influencia que las reformas de 1965 podrían tener en las pautas y los procesos de inmigración. A tal extremo que los legisladores enfocaron toda su atención en las consecuencias que podía comportar reabrir las puertas a la inmigración procedente de Asia, y no en los efectos potenciales de la migración proveniente de América Latina. 
No obstante, por debajo del radar de la conciencia pública y política, la inmigración procedente del hemisferio occidental ${ }^{1}$ había aumentado sistemáticamente a partir de 1945, en especial la de México. La cuota más significativa de este movimiento era temporal y circular y, por consiguiente, casi invisible a la población. Durante el periodo de 1955 a 1959, entró en el país alrededor de medio millón de mexicanos por año, con un número exacto que fluctuaba alrededor de los 450.000 trabajadores temporales bajo el Programa Bracero y casi 50.000 residentes permanentes. Con estas cifras, era evidente que el hecho de suprimir el Programa Bracero derivaría en graves consecuencias sobre el flujo de personas entre México y Estados Unidos. Menos evidente, pero también importante, era el hecho de que las enmiendas de $1965^{2}$, a la vez que abolían las cuotas discriminatorias por orígenes nacionales, imponían límites numéricos a la inmigración proveniente del continente americano por primera vez, ajustando los visados a un tope hemisférico de 120.000 en 1968. En 1976, la inmigración proveniente de todos los países del hemisferio occidental se limitó a 20.000 visados anuales. El Congreso abolió, en 1978, los límites por hemisferio y, en 1980, redujo el número de visados para todo el mundo a 270.000 .

Como resultado, desde finales de la década de 1950 hasta el final de la de 1970, México pasó de tener acceso a unos 450.000 visados temporales de trabajo y, en teoría, de un número ilimitado de visados de residencia (en la práctica, alrededor de 50.000 por año), a una nueva situación en la que no existían más visados de trabajo temporal y únicamente había 20.000 de residencia. La figura 1 ilustra el efecto predictible de estos nuevos límites en el sistema de inmigración de mexicanos desarrollado durante la época del Programa Bracero. Dicha figura muestra la entrada de mexicanos en Estados Unidos durante el periodo de 1955 a 1995 bajo tres categorías legales: inmigrantes temporales (braceros antes de 1965 y con otros visados temporales posteriormente); inmigrantes legales (con visados de residencia permanente) e inmigrantes ilegales (representados aquí por la cifra anual de detenciones por cada mil agentes de la Patrulla Fronteriza). Es evidente que el recuento de detenciones es un indicador imperfecto del volumen de la inmigración ilegal, pero ofrece, sin embargo, una medida razonable del flujo una vez controlados los esfuerzos por aplicar la ley, lo que se logró dividiendo el número de extranjeros detenidos por el número de agentes de la Patrulla Fronteriza (que los rastreaban).

Con los esfuerzos por aplicar la ley ya estandarizados, las tendencias en las detenciones reflejan principalmente los cambios en el volumen de ingresos de indocumentados a lo largo del tiempo. Es cierto que, cuando comparamos esta serie con una estimación independiente del flujo bruto anual de inmigrantes indocumentados mexicanos, derivado del Mexican Migration Project (descrito

1. En la ley norteamericana, el término hace referencia a los países de Norteamérica, Centroamérica, Sudamérica y el Caribe.

2. Se refieren a cambios importantes en la ley básica de inmigración (Inmigration and Nationality Act) aprobados por el congreso de los Estados Unidos en 1965. 
más adelante), se obtuvo la correlación de 0,767. A mediados de la década de 1960, un flujo circular masivo de inmigrantes mexicanos se había establecido firmemente en las prácticas patronales y era sostenido por redes de inmigrantes bien construidas y ampliamente accesibles a ellos (Massey et al., 2002). Como resultado, cuando, en 1965, se cortaron de raíz las rutas legales de entrada, los flujos migratorios no desaparecieron, sino que simplemente continuaron con otras características, sin ningún tipo de autorización ni documentos.

Como se muestra en la figura 1, el final del Programa Bracero corresponde exactamente al aumento de la inmigración ilegal. Desde una cifra aproximada de 40.000 personas detenidas en 1965 por cada 1.000 agentes, aumentó continuamente a un máximo aproximado de 460.000 en 1977. Posteriormente, entre 1978 y 1986, empezó a fluctuar entre 330.000 y 460.000 detenciones para después caer el intervalo a 240.000-320.000 detenciones anuales tras la aprobación de la Immigration Reform and Control Act (IRCA), en 1986. La IRCA ofreció un estatus legal a millones de indocumentados, quienes con anterioridad cruzaban constantemente la frontera de un lado al otro. Ello contribuyó al recuento anual de detenciones.

En resumen, la migración ilegal aumentó después de 1965, no por causa de una oleada de inmigración de mexicanos en sí misma, sino a causa de haber

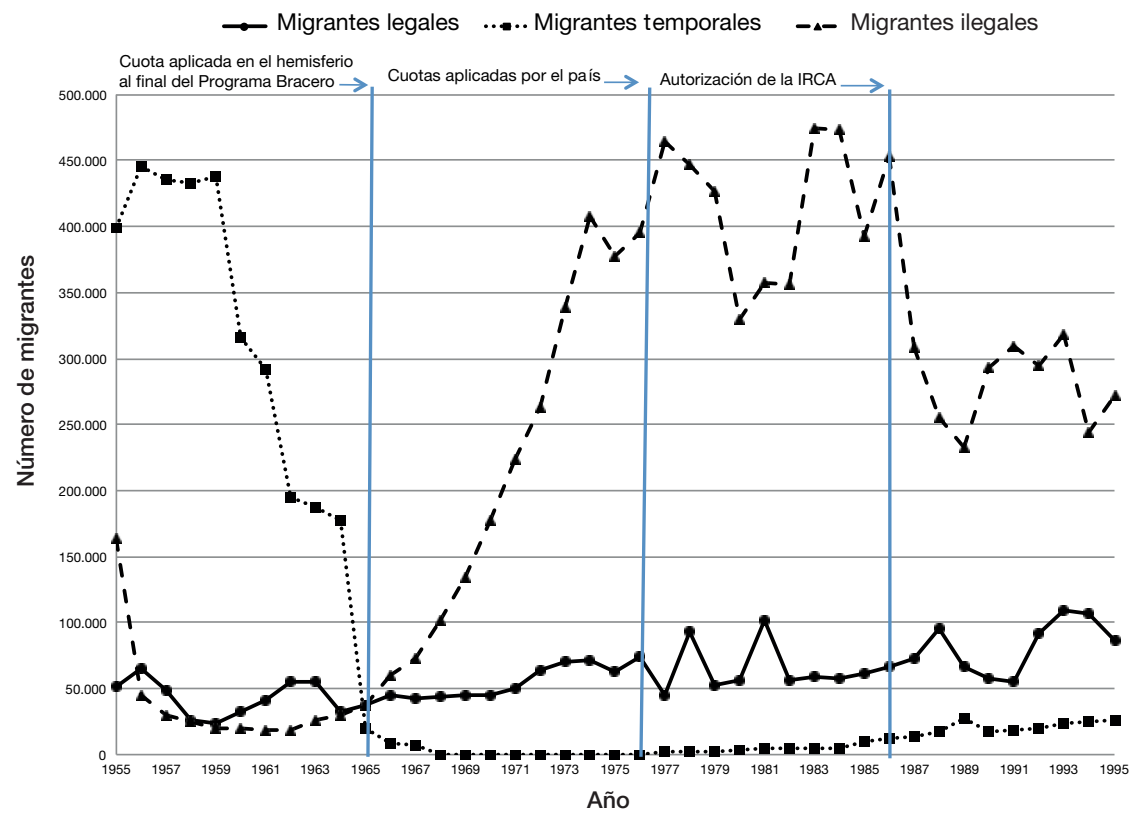

Figura 1. Migración de México a Estados Unidos en tres categorías diferentes.

Fuente: Office of Immigration Statistics. US Department of Homeland Security (http://www.dhs.gov/files/ statistics/immigration.shtm). 
cancelado el programa de trabajo temporal y de haber restringido el número de visados permanentes de residencia a 20.000 , lo cual dejaba sin una vía legal a los flujos ya bien establecidos. La inmigración legal anual proveniente de México permaneció por debajo de 50.000 personas hasta el inicio de la década de 1970, pero, a partir de entonces, empezó a fluctuar entre 50.000 y 100.000 inmigrantes anuales. El número de inmigrantes legales pudo exceder el tope de 20.000 establecido por ley, ya que los padres, las esposas y los hijos menores de ciudadanos de los Estados Unidos estaban exentos de cualquier tipo de limitación numérica. Sin embargo, esta exención era insuficiente para absorber la demanda de visados de entrada originada por la finalización del Programa Bracero.

En las series de inmigración legal, hemos dejado de lado los inmigrantes legalizados bajo la IRCA, lo que abultó artificialmente la cifra de inmigrantes legales entre 1988 y 1992. Su entrada ya está recogida en la serie de inmigración ilegal. El objetivo principal de la figura 1 es mostrar que, debido a la falta de una ruta de entrada legal, el incremento de la inmigración ilegal posterior a 1965 puede atribuirse casi totalmente a la finalización del Programa Bracero, y una vez que el statu quo de inmigración circular se había restablecido bajo la forma de indocumentados a finales de la década de 1970, el crecimiento de la migración ilegal se detuvo para, finalmente, descender tras la iniciativa de regularización de la IRCA.

\section{El surgimiento de la narrativa de la amenaza latina}

El aumento de la migración ilegal de 1965 hasta el final de la década de 1970 es de una importancia vital para entender la dinámica de la migración ilegal en los años siguientes, porque este desarrollo hizo posible que los activistas políticos y la burocracia empresarial encuadraran la inmigración de latinos como una amenaza grave para la nación. Chávez $(2001,2008)$ ha documentado el surgimiento de lo que él llama la «narrativa de la amenaza latina» en los medios de información americanos a partir de la década de 1960. Cuando revisó las portadas de las revistas sobre la inmigración para clasificarlas como positivas, negativas o neutrales, encontró un incremento sostenido de representaciones negativas a lo largo de las décadas de 1970, 1980 y 1990. El aumento en la narrativa de la amenaza latina se llevó a cabo, desde luego, en una época de incremento de la desigualdad en los ingresos y, como señala Fiske (2011: 89), «el sentirse despojado en lo individual [...] puede alertar a una persona a sentirse despojada colectivamente [...] [y] este sentir colectivo conduce a culpar a los grupos de extraños (inmigrantes, élites económicas, el partido en el poder)».

La descripción más común y negativa mostró la inmigración como una «crisis» para la nación. Al inicio, se utilizaron metáforas marinas para representar, de manera despectiva, el debate de la crisis sobre la inmigración de latinos como «aumento de la marea» o una "crecida» que iba a «inundar» Estados Unidos y «ahogar» su cultura, al mismo tiempo que «abarrotar» la sociedad americana con extranjeros indeseados (Santa Ana, 2002). Con el tiempo, sin 
embargo, las metáforas marinas dieron paso al imaginario bélico. La inmigración era representada como una "invasión» en la cual los agentes "desarmados» de la Patrulla Fronteriza buscaban "contener la línea» en un intento en vano por «defender» la frontera en contra de los «ataques» de los «invasores extranjeros», quienes efectuaban "ataques suicidas» a defensores inermes (Nevins, 2001; Santa Ana, 2002; Chávez, 2008).

Para constatar el aumento en el uso de estas metáforas, acudimos a los archivos del periódico Proquest Historical, para buscar ejemplos en los que las palabras «indocumentados», «ilegales» o «no autorizados» se emparejaban con «México» o «inmigrantes mexicanos», así como con las palabras "crisis», «flujo» o «invasión». Concentramos nuestro análisis en cuatro de los periódicos más importantes del país: The New York Times, The Washington Post, The Wall Street Journal y Los Angeles Times. Para controlar los efectos aleatorios y aislar las tendencias subyacentes, calculamos medias móviles de tres años de las frecuencias resultantes para trazar los resultados en la figura 2. Puede observarse que, en 1965, casi no existía el uso de metáforas negativas para describir la inmigración de mexicanos, al menos en la mayoría de los periódicos, pero, a partir de ese año, aumentaron sistemáticamente, al principio con lentitud, pero, a partir de la década de 1970, con más rapidez hasta alcanzar su máximo

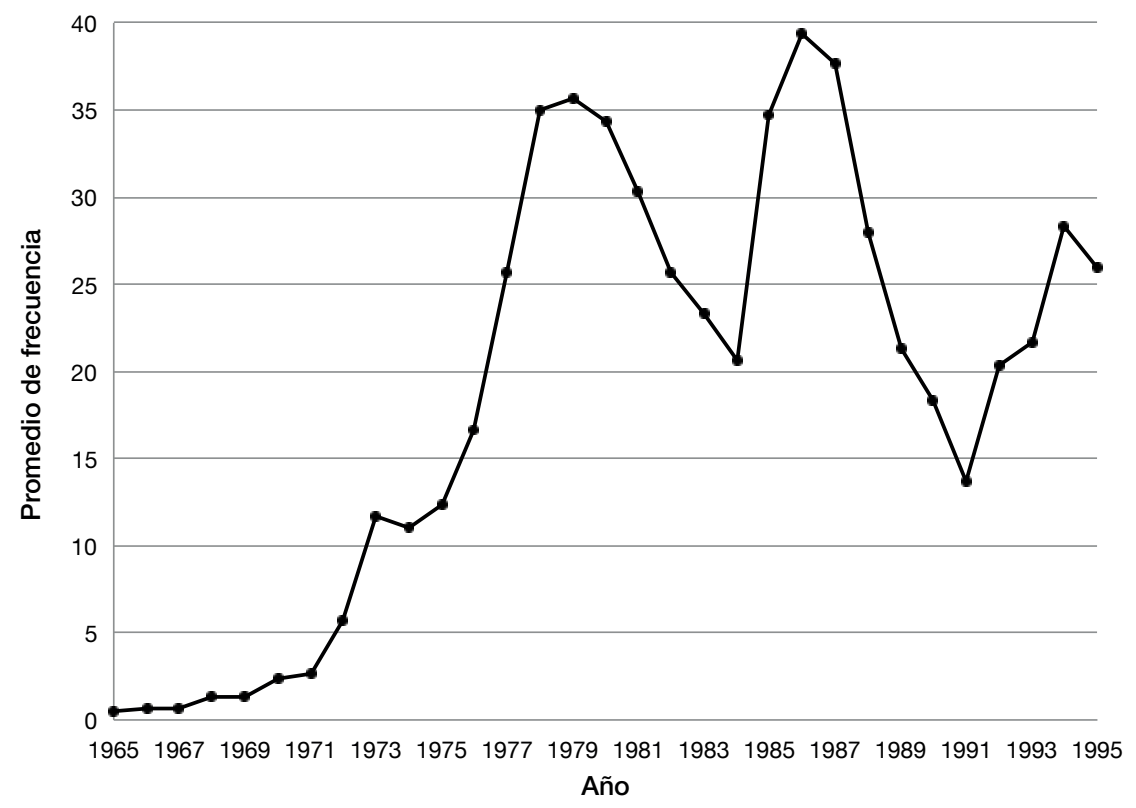

Figura 2. Frecuencia de aparejar los términos inundar, crisis o invasión con inmigración en cuatro importantes diarios (medias móviles de tres años).

Fuente: elaboración propia a partir de archivos del ProQuest Historical Newspaper Files. 
al final de la década de 1970, casi al mismo tiempo en que la migración ilegal alcanzara su máximo. Efectivamente, entre 1965 y 1977, la correlación entre la serie de inmigración ilegal mostrada en la figura 1 y la serie de metáforas negativas mostrada en la figura 2 es de 0,911 .

Las autoridades de inmigración catalogaron a esta como «crisis» y difundieron ampliamente el uso del imaginario bélico. Por ejemplo, en 1976, el Comisionado del Servicio de Inmigración y Naturalización (INS) publicó un artículo en Reader's Digest intitulado «Ilegal Aliens: Time to Call a Halt!», en el que alertaba a los americanos sobre "cuando me convertí en el comisionado [del INS] en 1973, no contábamos con vehículos, teníamos poco presupuesto y nos enfrentábamos a una creciente y silenciosa invasión de extranjeros ilegales. A pesar de nuestros esfuerzos, el problema - crítico en aquel momentohoy amenaza en convertirse en un desastre nacional» (Chapman, 1976: 188). Igualmente, el jefe del sector San Diego de la Patrulla Fronteriza, Gustavo de la Viña, filmó y exhibió, en 1992, un vídeo titulado Border Under Siege, donde se mostraba una dramática escena en la que inmigrantes apiñados en automóviles entorpecían el tráfico en la carretera Interestatal 5 para entrar en Estados Unidos por San Ysidro sin ningún tipo de inspección, en aquel momento, el punto de entrada más transitado (Rotella, 1998).

Los políticos descubrieron de inmediato las ventajas de satanizar a los inmigrantes latinos. Ronald Reagan, por ejemplo, aseveró que la inmigración ilegal era una cuestión de «seguridad nacional» y, en un discurso en 1986, dijo a los americanos que «terroristas y subversivos se encuentran a dos días de viaje en automóvil de [la frontera que cruza a] Harlingen, Texas» (citado en Kamen, 1990). El gobernador de California, Pete Wilson, en su campaña para buscar la reelección de 1992, fue llamado a Washington para «detener la invasión» y tomó prestado partes del vídeo Border Under Siege para publicar una serie de anuncios sobre ataques. Cuando se mostraban las imágenes de los inmigrantes corriendo y escabulléndose entre los automóviles, el locutor decía «siguen llegando. Dos millones de inmigrantes ilegales a California. El gobierno federal no los puede detener en la frontera y aun así debemos pagar millones de dólares por hacernos cargo de ellos» (Massey et al., 2002).

En años posteriores, los expertos se unieron al coro en contra de los inmigrantes para atraer la atención y vender sus libros, con Lou Dobbs (2006) refiriéndose a la «invasión de extranjeros ilegales» como parte de una "guerra contra la clase media» más generalizada. Patrick Buchanan (2006) la amplió como parte de un "Complot Aztlán" maquinado por los mexicanos para recuperar los territorios perdidos en 1848 , diciendo que «si no tomamos el control de nuestras fronteras y detenemos la invasión más grande de la historia, veo la disolución de Estados Unidos con la pérdida del sur del país» (Time, 28 de agosto, p. 6). Samuel Huntington (2004), desde su encumbrada silla de Harvard, advirtió a los americanos que «la entrada constante de los inmigrantes hispanos amenaza con dividir Estados Unidos en dos pueblos, dos culturas, dos idiomas [...] Estados Unidos ignora este desafío a su propio riesgo». 


\section{Efectos sobre la opinión pública}

El cambio en las medidas legales de la inmigración de mexicanos transformó lo que había sido, durante largo tiempo, una circulación invisible de inofensivos inmigrantes braceros en una violación a la soberanía de Estados Unidos por invasores y criminales extranjeros, que cada año iba en aumento. La inclemente propaganda que acompañó este cambio tuvo un efecto poderoso en la opinión pública. La convirtió claramente en más conservadora, no sólo en los temas relacionados con la inmigración, sino también por lo que respecta a los temas sociales de manera más general. El crecimiento de la inmigración de ilegales aún no se reconoce como factor en el cambio de rumbo hacia posiciones más conservadoras en la opinión del pueblo americano. Para apoyar esta idea, se extrajo información de la General Social Survey (GSS), desde su inicio, en 1972, hasta la fecha y estimamos el efecto que la cifra de detenciones en la frontera tuvo sobre la probabilidad de que un encuestado se definiera a sí mismo como conservador, guiado por características demográficas, sociales y económicas individuales, así como por el clima económico de la nación en su conjunto (medido en términos de ingresos esperados o la probabilidad anual de empleo multiplicada por el ingreso promedio semanal en dólares estadounidenses de 2010). Utilizamos el total de detenciones en vez de las detenciones estandarizadas (por ejemplo: detenciones divididas por agentes), porque se trata de una estadística difundida con regularidad en la prensa y pregonada una y otra vez por los actores políticos y la burocracia empresarial para movilizar los distritos electorales y asegurar su poder e influencia.

Como muestra la tabla 1, las detenciones en la frontera ejercen un efecto poderoso sobre la probabilidad de identificarse a sí mismo como conservador. $\mathrm{Al}$ aumentar la cifra de detenciones de su mínimo a su máximo, casi se duplican las probabilidades de que un encuestado se identifique como conservador, manteniendo constante un conjunto diverso de características básicas y el clima económico en general. En el curso del análisis descrito a continuación, utilizamos, entonces, el porcentaje de quienes se identifican como conservadores para indicar el alcance de la reacción en contra de los inmigrantes en un año dado. Lo ideal habría sido medir directamente los sentimientos de exclusión, pero la encuesta (GSS) incluyó únicamente preguntas detalladas sobre las actitudes hacia la inmigración en 1996 y 2004.

En la tabla 2, se utiliza la información de estos años para documentar la fuerte asociación entre el conservadurismo y el apoyo a las políticas de exclusión hacia los inmigrantes. Empezamos por desarrollar un índice de apoyo a las políticas de exclusión hacia los inmigrantes, al combinar las respuestas de los encuestados a dos preguntas sobre el grado de acuerdo con el enunciado de "Los americanos deberían excluir a los inmigrantes ilegales», y si pensaban que «La cifra actual de inmigrantes debería aumentar o disminuir». Las respuestas para la primera pregunta se catalogaron en: 4) de acuerdo totalmente; 3) de acuerdo; 2) ni de acuerdo ni en desacuerdo; 1) en desacuerdo, y 0) en des- 
acuerdo totalmente. Las respuestas a la segunda pregunta fueron: 0) aumentó mucho; 1) aumentó poco; 2) permanece igual; 3) se redujo un poco, y 4) se redujo bastante. Al combinar las respuestas de las dos preguntas, se llegó a una escala de 0-8 en apoyo a las políticas de exclusión. Luego calculamos una regresión de mínimos cuadrados («OLS regression») que expresaba el nivel de apoyo a las políticas de exclusión como una función del grado de autoidenti-

Tabla 1. Modelo de regresión logística que predice el efecto de las detenciones sobre la probabilidad de identificarse como conservador. Respuestas de la General Social Survey (1972-2010)

\begin{tabular}{|c|c|c|}
\hline Variables independientes & B & SE \\
\hline \multicolumn{3}{|l|}{ Antecedente demográfico } \\
\hline Edad & $0,0113^{\star \star}$ & 0,0035 \\
\hline Edad al cuadrado & 0,0000 & 0,0000 \\
\hline Mujer & $-0,1818^{\star * *}$ & 0,0215 \\
\hline Blanco & $0,3532^{* * *}$ & 0,0287 \\
\hline Nacido en Estados Unidos & 0,0139 & 0,0289 \\
\hline Casado en la actualidad & $0,2479^{\star \star \star}$ & 0,0214 \\
\hline Menores en el hogar & $0,0552^{\star \star \star}$ & 0,0094 \\
\hline \multicolumn{3}{|l|}{ Antecedentes socioeconómicos } \\
\hline Educación & $0,0329^{\star * \star}$ & 0,0037 \\
\hline Ingresos & $0,0021^{\star \star *}$ & 0,0003 \\
\hline \multicolumn{3}{|l|}{ Antecedentes ocupacionales } \\
\hline Ocupación calificada & - & - \\
\hline Ocupación profesional & $-0,0422$ & 0,0273 \\
\hline Ocupación en servicios & 0,0269 & 0,0250 \\
\hline Ocupación en la agricultura & 0,0365 & 0,0676 \\
\hline \multicolumn{3}{|l|}{ Región de Estados Unidos } \\
\hline Occidente & - & - \\
\hline Noreste & $-0,2168^{\star \star \star}$ & 0,0323 \\
\hline Medio oeste & $-0,0218$ & 0,0295 \\
\hline Sur & $0,1734^{* \star *}$ & 0,0279 \\
\hline \multicolumn{3}{|l|}{ Tamaño de la ciudad } \\
\hline Rural & - & \\
\hline Ciudad urbana grande & $-0,2395^{\star \star \star}$ & 0,0412 \\
\hline Ciudad urbana media & $-0,1140^{\star \star \star}$ & 0,0309 \\
\hline Ciudad urbana pequeña & $-0,0078$ & 0,0240 \\
\hline \multicolumn{3}{|c|}{ Contexto económico en Estados Unidos } \\
\hline Ingresos esperados & $-0,0027^{\star \star *}$ & 0,0004 \\
\hline \multicolumn{3}{|c|}{ Contexto de políticas en Estados Unidos } \\
\hline Detenciones a mexicanos & $0,1680^{\star \star \star}$ & 0,0315 \\
\hline \multicolumn{3}{|l|}{ Logaritmo de verosimilitud 1263,2685} \\
\hline \multicolumn{3}{|l|}{ Chi-cuadrado de Wald $1189,8908^{\star \star \star}$} \\
\hline Número de observaciones 51.981 & & \\
\hline
\end{tabular}


ficación conservadora, controlando la situación por el clima económico y las características demográficas sociales y económicas individuales.

Como puede observarse, cuanto más se identifique una persona como conservadora, más probable resulta que apoye las políticas de restricción a la inmigración. Quienes se identificaron como conservadores moderados tienen un valor en el índice de exclusión de 0,40 puntos más grande que quienes no

Tabla 2. Modelo que predice el apoyo a las políticas de restricción a la inmigración en 1996 y 2004 desde una identificación conservadora: General Social Survey

\begin{tabular}{|c|c|c|}
\hline Variables independientes & B & SE \\
\hline \multicolumn{3}{|l|}{ Antecedentes demográficos } \\
\hline Edad & $0,0351^{\star \star}$ & 0,0138 \\
\hline Edad al cuadrado & $-0,0002^{*}$ & 0,0001 \\
\hline Mujer & $-0,1113$ & 0,0918 \\
\hline Blanco & $0,5176^{\star \star}$ & 0,1597 \\
\hline Casado en la actualidad & $0,2474^{\star \star}$ & 0,1094 \\
\hline Menores en el hogar & $-0,0150$ & 0,0403 \\
\hline \multicolumn{3}{|l|}{ Antecedente socioeconómico } \\
\hline Educación & $-0,0793^{\star \star *}$ & 0,0183 \\
\hline \multicolumn{3}{|l|}{ Capital humano específico } \\
\hline Ingreso (x 1.000) & $-0,0016$ & 0,0013 \\
\hline \multicolumn{3}{|l|}{ Antecedente ocupacional } \\
\hline Ocupación calificada & - & - \\
\hline Ocupación profesional & $-0,1017$ & 0,0885 \\
\hline Ocupación en servicios & 0,0235 & 0,0852 \\
\hline Ocupación en la agricultura & $-0,0526$ & 0,3130 \\
\hline \multicolumn{3}{|l|}{ Región de Estados Unidos } \\
\hline Occidente & - & - \\
\hline Noreste & 0,1012 & 0,1512 \\
\hline Medio oeste & 0,1187 & 0,0982 \\
\hline Sur & $0,2608^{\star *}$ & 0,1062 \\
\hline \multicolumn{3}{|l|}{ Tamaño de la ciudad } \\
\hline Rural & - & \\
\hline Ciudad urbana grande & $-0,3992^{\star \star}$ & 0,1667 \\
\hline Ciudad urbana media & $-0,1258$ & 0,0784 \\
\hline Ciudad urbana pequeña & $-0,1302$ & 0,1056 \\
\hline \multicolumn{3}{|l|}{ Identificación política } \\
\hline No conservadora & - & - \\
\hline Algo conservadora & $0,3959^{\star \star \star}$ & 0,1018 \\
\hline Extremadamente conservadora & $0,5572^{\star \star}$ & 0,1520 \\
\hline \multicolumn{3}{|l|}{$\mathrm{R}$ cuadrado ajustado 0,037} \\
\hline \multicolumn{3}{|l|}{ Prueba F $11,47^{\star \star \star}$} \\
\hline Número de observaciones 5.194 & & \\
\hline
\end{tabular}


se identificaron como conservadores, mientras que aquellos que se identificaron como extremadamente conservadores tienen un valor que es 0,56 puntos más elevado. Ambos efectos son igualmente significativos y continúan persistiendo a pesar de los controles de la edad (asociados con el incremento del apoyo a la exclusión), del hecho de ser blanco (también apoyo incrementado), del nivel de educación (apoyo reducido), de la residencia en el sur (apoyo incrementado) y de la residencia en grandes áreas urbanas (apoyo reducido). El punto central es que el sentir general de conservadurismo y de exclusión están fuertemente relacionados.

\section{Efectos sobre las políticas públicas}

En esta sección, se muestra que el aumento de la amenaza latina en la narrativa y el crecimiento consecuente en el conservadurismo estuvo asociado en el tiempo con la aprobación de las leyes de restricción a la inmigración, que iban en aumento, y la puesta en marcha de políticas para aplicar la ley aún más rigurosas. La tabla 3 ofrece un listado acumulado de quince proyectos de ley aprobados que restringen la inmigración entre 1965 y 2010. Como se observa, y conforme transcurre el tiempo, los proyectos de ley sobre restricciones se aprueban a un ritmo extraordinariamente acelerado. Por ejemplo, en treinta años, de 1965 a 1995, se aprobaron únicamente seis proyectos importantes de ley, pero de 1996 a 2006, solamente ocho. La actividad legislativa contra los inmigrantes empezó a acelerarse en la década de 1990 e iba acompañada del lanzamiento de un conjunto de operaciones especiales de las autoridades legislativas, que empezó con la Operation Blockade en 1993 y terminó más recientemente con la Operation Cooper Cactus en 2010. Como se muestra en la tabla 4, durante ese periodo, se lanzaron un total de dieciséis de las llamadas "operaciones para aplicar la ley», que, por lo general, se anunciaban a bombo y platillo, incluida la divulgación oficial, los comunicados de prensa y la extensa cobertura por parte de los medios de información. Con el tiempo, estas operaciones se han ido generalizando cada vez más y han llegado a cubrir diversas localidades dentro de Estados Unidos y la zona fronteriza entre México y Estados Unidos.

La acumulación sostenida y acelerada de leyes contra los inmigrantes, al igual que las operaciones para aplicar la ley, fueron las responsables inmediatas de la escalada masiva de detenciones en la frontera y en el territorio estadounidense, así como de las deportaciones (mencionadas al inicio de este trabajo), las que en conjunto constituyen el objetivo de la guerra contra los migrantes. Estos aumentos garantizan un buen número de detenciones cada año, sin tomar en cuenta el tráfico migratorio subyacente. Para un número dado de ingresos de indocumentados, surge una legislación más restrictiva y operaciones para aplicar la ley más rigurosas que generan, a su vez, más detenciones, utilizadas por los políticos y los funcionarios para exacerbar la opinión pública, lo que lleva a que los votantes exijan leyes aún más restrictivas, más operaciones para aplicar la ley, más detenciones y así lograr un proceso de retroalimentación circular. 
Tabla 3. Legislación de restricción a la inmigración aprobada por el Congreso en contra de los latinoamericanos (1965-2010)

1965 Hart-Cellar Act

Límite de 120.000 visas para inmigrantes del hemisferio occidental impuesto por vez primera.

1976 Amendments to Immigration and Nationality Act

Coloca al hemisferio occidental como sistema preferente con cuotas por país.

1978 Amendments to Immigration and Nationality Act

Combinación de límites separados en los hemisferios a un tope de 290.000 a nivel mundial.

1980 Refugee Act

Abolición de la preferencia de refugiado y reducción a un límite de 270.000 a nivel mundial.

1986 Immigration Reform and Control Act

Castigo por emplear indocumentados y autorización para expandir la Patrulla Fronteriza.

1990 Amendments to the Immigration and Nationality Act

Estableció los límites a visas dirigidas a esposas e hijos menores de extranjeros residentes.

1996 Antiterrorism and Effective Death Penalty Act

Autorización expedita para expulsar extranjeros y deportación por agravio criminal.

1996 Illegal Immigrant Reform and Immigrant Responsibility Act

Aumento de recursos para ejercer la ley en la frontera, criterios cerrados para otorgar asilo y aumento en el mínimo de ingresos para hacerse cargo de inmigrantes.

1996 Personal Responsibility and Work Opportunity Act

Declaración para migrantes legales e ilegales como no aptos para llevar a cabo ciertas actividades.

1997 Nicaraguan and Central American Relief Act

Autorización de EUA para otorgar asilo a centroamericanos (mayormente, nicaragüenses), por lo menos durante cinco años a partir del 1 de enero de 1995, para obtener su residencia legal; pero se prohíbe la legalización con orden de deportación para quienes no cuenten con una visa vigente o para quienes hayan violado con anterioridad las leyes de migración de EUA (en su mayoría, hondureños, salvadoreños y guatemaltecos).

2001 USA Patriot Act

Establecido por el Department of Homeland Security, aumento de fondos para vigilancia y deportación de extranjeros; autorización para deportar extranjeros sin un proceso legal.

2004 National Intelligence Reform and Terrorism Protection Act

Equipo nuevo, aviones, agentes de Patrulla Fronteriza, personal para investigar a los migrantes y centros de detención por violar la ley en la frontera.

2005 Real ID Act

Aumento de innumerables solicitudes de información, documentación y procedimientos de verificación en la emisión de licencias de manejo estatales.

2006 Secure Fence Act

Autorización para construir bardas adicionales, barreras para vehículos, puntos de revisión, alumbrado y fondos para cámaras nuevas, colocar satélites y sirenas en despoblado a lo largo de la frontera.

2010 Border Security Act

Fondos para contratar a 3.000 agentes más de la Patrulla Fronteriza, con lo cual se aumenta su presupuesto a 244 millones de dólares. 
Tabla 4. Emisión de operaciones restrictivas para ejercer la ley migratoria por el Immigration and Naturalizacion Service y por el Homeland Security (1990-2010)

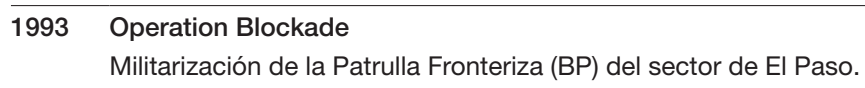

1994 Operation Gatekeeper

Militarización de la BP del sector de San Diego.

1998 Operation Rio Grande

Programa de la BP para restringir el movimiento de migrantes de Texas y Nuevo México en la frontera con México.

1999 Operation Safeguard

Militarización de la BP del sector de Tucson.

2003 Operation Endgame

Plan lanzado por Immigration and Customs Enforcement para detener y deportar a extranjeros removibles y "sospechosos de terrorismo» que viven en Estados Unidos.

2004 Operation Frontline

Programa lanzado por Immigration and Customs Enforcement (ICE) dirigido a «puntos vulnerables en inmigración y comercio", enfocándose en quienes violan la inmigración con el fin de «aumentar la seguridad pública o [evitar] una amenaza a la seguridad nacional».

2004 Arizona Border Control Initiative

Organismo múltiple de apoyo en los esfuerzos de la Homeland Security en su misión para combatir el terrorismo, detectando, arrestando y frenando a todos aquellos involucrados en actividades ilícitas en el cruce de la frontera.

2004 Operation Stonegarden

Programa federal administrado por el State Homeland Security Grant Program, que otorga fondos a los estados y a los organismos locales, con el fin de mejorar el cumplimiento de la ley migratoria.

2005 Secure Borders Initiative

Plan que comprende varios años, lanzado por el ICE para asegurar las fronteras de EUA y reducir la migración de ilegales.

2005 Operation Streamline

Decreto que ordena cargos de orden criminal a ilegales aún en su primera infracción.

2006 Operation Return to Sender

Operación del ICE para devolver inmigrantes detenidos hacia México sin derecho a juicio.

2006 Operation Jump Start

Programa que autoriza el despliegue de las tropas de la Guardia Nacional de EUA a lo largo de la frontera entre México y Estados Unidos.

2007 Secure Communities Program

Programa del ICE que identifica y deporta extranjeros criminales arrestados por autoridades estatales y municipales.

2007 Operation Rapid REPAT

Programa Remove Eligible Parolees Accepted for Transfer, que permite a extranjeros encarcelados en EUA aceptar su libertad anticipada a cambio de la deportación voluntaria.

2008 Operation Scheduled Departure

Programa del ICE que posibilita la deportación voluntaria de 457.000 migrantes ilegales de ciudades elegidas.

2010 Operation Copper Cactus

Despliegue de las tropas de la Arizona National Guard para ayudar a la BP en la detención de migrantes ilegales. 
En resumen, el aumento de la inmigración ilegal, su formulación como una amenaza a la nación y el resultado de la reacción conservadora dio lugar a una cadena de reacción retroalimentada de aplicación de la ley, que generó más detenciones, aunque el flujo real de inmigrantes indocumentados se había estabilizado al final de la década de 1970 y había descendido en las de 1980 y 1990. En otras palabras, la «invasión» de inmigrantes indocumentados estuvo maquinada, básicamente, por las políticas de Estados Unidos, con un fuerte respaldo por parte de políticos oportunistas que buscaban movilizar a los votantes, de funcionarios ambiciosos en obtener recursos y de medios de información sensacionalistas que buscaban una historia que vender. El único problema es que la historia no era cierta.

Las dimensiones de esta paradoja se ilustran en la figura 3, que contrasta las entradas ilegales estimadas con el total de detenciones. Cuando estandarizamos según los esfuerzos por aplicar la ley, observamos el aumento de la migración ilegal de 1965 a 1977, en la medida en que se restablece la circulación de la era Bracero, niveles que descienden a partir de entonces y fluctúan hasta finalmente caer. En contraste, la cifra total de detenciones se mantiene al alza a un ritmo acelerado, para alcanzar 1,6 millones en 1986, antes de descender a alrededor de 900.000 y luego acelerar su crecimiento hasta los 1,3 millones en 1995. Como es de esperar, la variación temporal en la cifra total de deten-

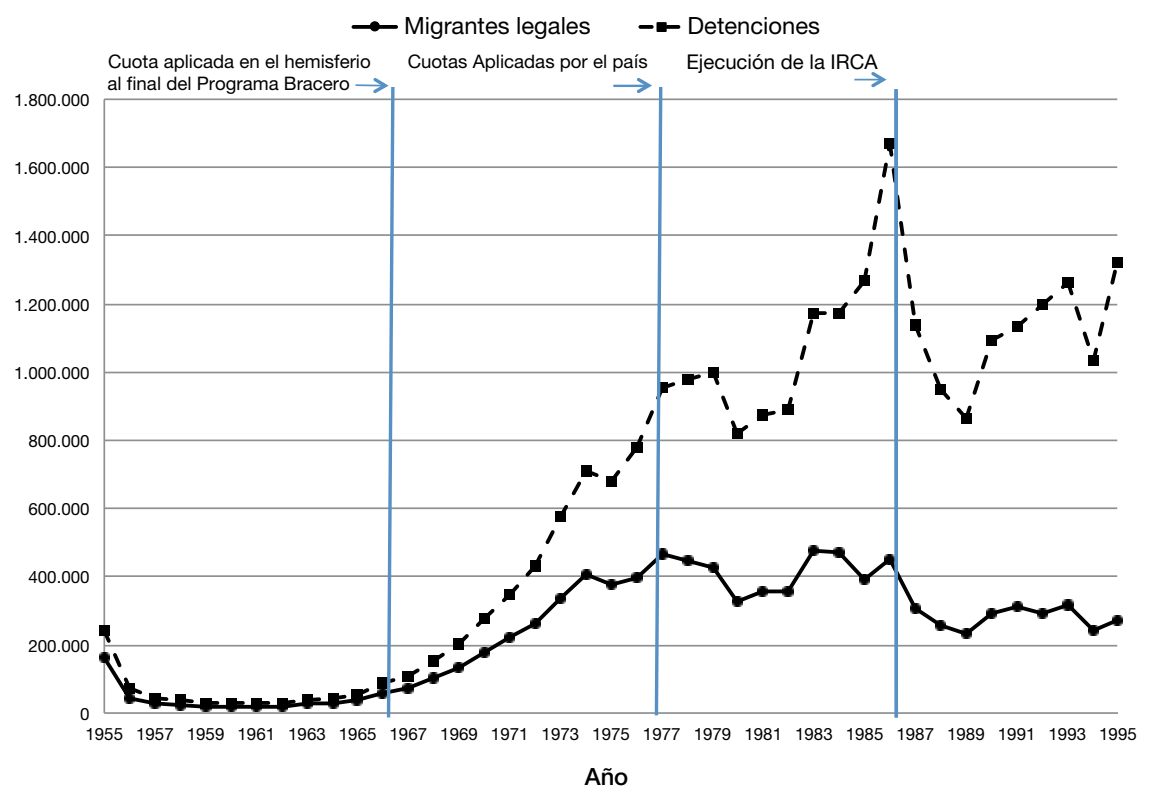

Figura 3. Detenciones versus migrantes ilegales.

Fuente: Office of Immigration Statistics. US Department of Homeland Security (http://www.dhs.gov/files/ statistics/immigration.shtm). 
ciones se relaciona con el uso de metáforas amenazantes sobre la inmigración. De 1965 a 1995, la correlación entre la frecuencia de alusiones en la prensa a crisis, inundaciones e invasiones, y la cifra total de detenciones es de 0,956.

Después de 1970, por lo tanto, la histeria contra los migrantes se retroalimentaba más y más para llevar a la maquinaria burocrática de aplicación de la ley hacia nuevos horizontes, a pesar de que no se producía un aumento real en la inmigración ilegal. En la figura 4, se modela esta trayectoria dependiente utilizando una estrategia de estimación de mínimos cuadrados en dos etapas sobre series de tiempo para un periodo de treinta años, de 1965 a 1995. La información sobre detenciones, el número de agentes de la Patrulla Fronteriza, el volumen del presupuesto de la Patrulla Fronteriza y el número de horas de vigilancia en la línea fronteriza se obtuvo de la Office of Immigration Statistics of the US Department of Homeland Security (2012). La cifra de proyectos de leyes restrictivas aprobados y las operaciones restrictivas puestas en marcha se codificaron a partir de los cuadros 3 y 4 , donde se indexaron como el total acumulado de leyes y de operaciones promulgadas en el año en cuestión.

El número de entradas de indocumentados se estimó de manera independiente utilizando la información de historias de vida obtenidas del jefe de familia por el Mexican Migration Project (MMP), un estudio binacional que entrevista anualmente a mexicanos en ambos lados de la frontera y utiliza la información obtenida para generar una base de datos acumulativa sobre patrones y procesos de migración de migrantes documentados e indocumentados

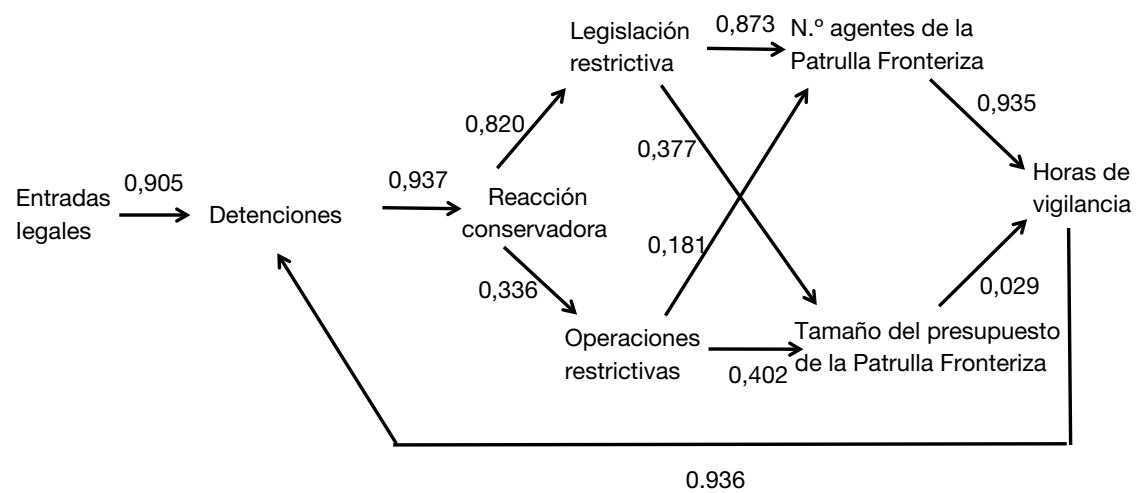

Efecto directo de entradas en la reacción conservadora por vía detenciones: 0,848.

Efecto mediante el ciclo de aplicación de la ley. Sendero principal: 0,626 y efecto total: 0,692 .

Figura 4. Ciclo de retroalimentación entre detenciones y aplicación de la ley en la frontera (1965-1995).

Fuente: Tabla A1 en MASSEY, Douglas S. y PREN, Karen A. (2012), «Unintended consequences of US Immigration Policy: Explaining the post-1965 surge from Latin America». Population and Development Review, 38 (1), 1-29. 
(http://mmp.opr.princeton.edu/). En el momento de escribir este trabajo, la base de datos contiene 21.475 historias de vida de jefes de familia, y cada caso incluye una historia completa de migración que puede ser utilizada para calcular las probabilidades anuales de inmigración ilegal (Massey et al., 2009). Aplicamos esta estimación de probabilidades al recuento anual de población derivado del Instituto Nacional de Estadística, Geografía e Informática (INEGI) de México, para estimar el flujo anual bruto de inmigrantes ilegales.

La cifra de entradas de indocumentados es un proceso exógeno al sistema de ecuaciones que define el ciclo de retroalimentación de políticas y ofrece, así, un instrumento adecuado para estimar este ciclo. La cadena causal empieza con el aumento de entradas de indocumentados, lo que genera más detenciones, y ello, por su parte, se transforma en una reacción conservadora contra los inmigrantes a través de las maquinaciones de la burocracia empresarial y los funcionarios ambiciosos. Reacción que origina, a su vez, leyes de inmigración más restrictivas y más operaciones en la frontera, que aumentan el número de agentes de la Patrulla Fronteriza y el volumen del presupuesto de la misma, lo cual origina más horas de vigilancia en la frontera y más detenciones. De esta manera, se realimenta el sistema para aumentar la reacción conservadora, independientemente del número real de entradas ilegales.

Como se muestra en la figura 4, el efecto de las entradas ilegales en el sentido de producir una reacción conservadora es de 0,848 , cifra obtenida mediante la variable interviniente de detenciones $(0,905 \times 0,937=0,848)$, que hace más visibles las entradas clandestinas presentadas por los políticos como una amenaza, lo cual produce una reacción conservadora que, por sí misma, induce una cadena de respuestas a las políticas establecidas que se acumulan a un efecto total sobre la reacción conservadora de 0,691 . Si bien este efecto de retroalimentación no es tan poderoso como el efecto exógeno de entradas $(0,845)$, es, sin embargo, lo suficientemente fuerte como para sostener un incremento de detenciones aun cuando las entradas sean constantes o ligeramente a la baja. De las dos trayectorias principales - la superior con una legislación restrictiva y la inferior con operaciones restrictivas en la frontera-, la primera es, con mucho, la más fuerte, 0,626, y supone el $90 \%$ del efecto total de retroalimentación. Por lo tanto, las detenciones producen una reacción conservadora que lleva a una legislación restrictiva que aumenta el número de agentes de la Patrulla Fronteriza, con más horas de vigilancia en la frontera que generan más detenciones, lo que aviva la reacción conservadora.

El resultado final de este ciclo de retroalimentación se señala en la figura 5, que muestra tres indicadores de intensidad de la aplicación de la ley en la frontera relativa al número de detenciones estandarizadas, nuestro indicador del tráfico subyacente de inmigrantes ilegales. Cada serie está dividida por su valor en 1977, año en el que la inmigración de indocumentados alcanzó su máximo nivel. Mientras que el número relativo de detenciones por mil agentes empezó a aumentar al final de la década de 1950 para alcanzar el 1,0 en 1977, y fluctuó a partir de entonces alrededor de 1 antes de caer por debajo de este valor, después de 1977 se duplicó el número de horas de vigilancia, el número de agentes 


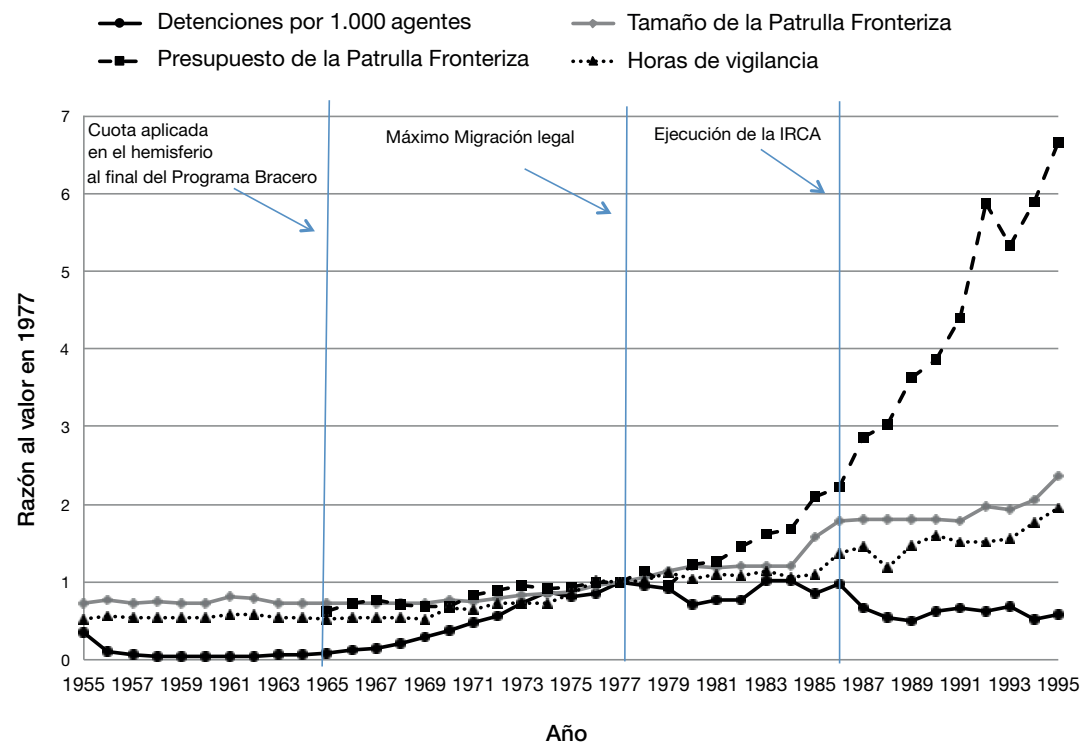

Figura 5. Intensidad de la aplicación de la ley (1965-1995).

Fuente: Office of Immigration Statistics. US Department of Homeland Security (http://www.dhs.gov/files/ statistics/immigration.shtm).

de la Patrulla Fronteriza aumentó en 2,5 veces y el presupuesto de la Patrulla Fronteriza se multiplicó por 6,5. Durante la década de 1970 y después de estos años, por decirlo en otras palabras, la militarización de la frontera estaba cada vez más desconectada del tráfico real de migrantes ilegales.

\section{Efecto de la guerra contra el terror}

El ciclo de retroalimentación que conecta detenciones, actitudes del público, legislación y aplicación de la ley migratoria estaba plenamente establecido alrededor de la década de 1990, cuando una serie de sucesos externos llevó a este ciclo de aplicación de la ley a otro nivel. Los graves ataques terroristas desencadenados en la década de 1990 e inicios de 2000 ayudaron a transformar la primera década del siglo XXI en una era de miedo e inseguridad en Estados Unidos. No hay duda de que, ya antes de los años noventa, existía un amplio temor material e ideológico por la ola visible de ataques terroristas y con blancos políticos iniciados en 1993, que llevaron consigo la histeria contra los extranjeros y la xenofobia a nuevos niveles. En respuesta al ataque de 1993 en el World Trade Center y, en 1995, a la explosión de una bomba en el Murrah Federal Building, en la ciudad de Oklahoma, el Congreso autorizó, en 1996, el Anti-Terrorism and Effective Death Penalty Act, el Illegal Immigrant Reform y el Immigrant Responsibility Act. Posteriormente al ataque, en 


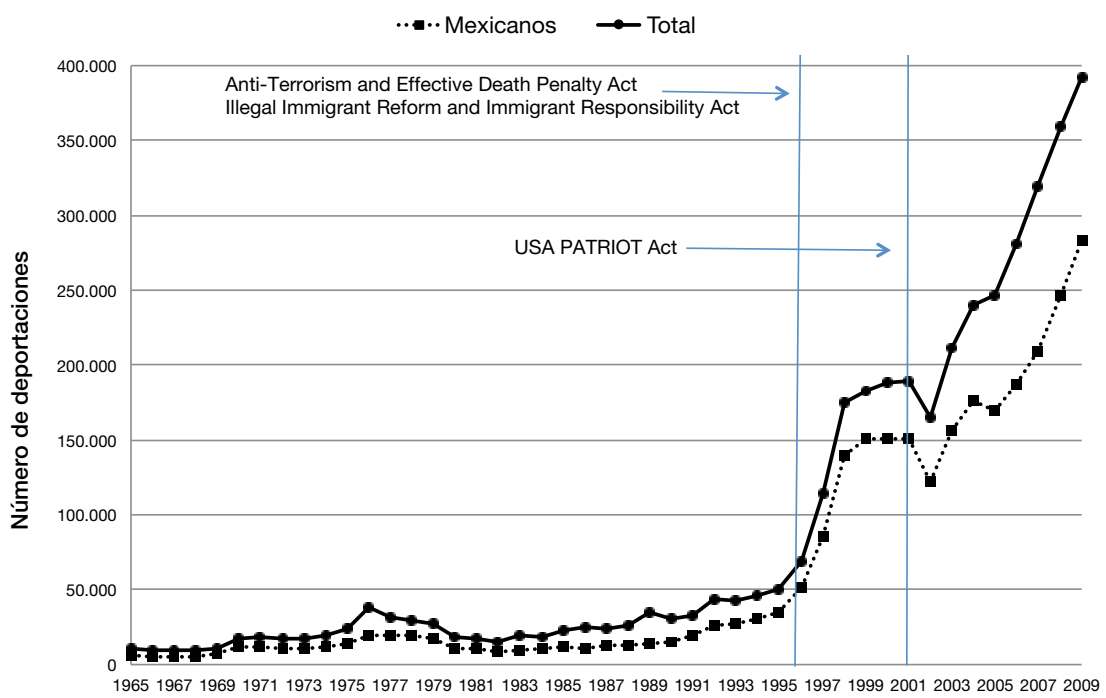

Año

Figura 6. Deportaciones desde Estados Unidos (1965-2009).

Fuente: Office of Immigration Statistics. US Department of Homeland Security (http://www.dhs.gov/files/ statistics/immigration.shtm).

1998, al USS Cole en Yemen, los atentados a las embajadas de Estados Unidos en Kenia y Tanzania en el año 2000 y los catastróficos ataques al World Trade Center y al Pentágono en 2001, el Congreso puso en marcha el USA PATRIOT Act.

Estas medidas no sólo reforzaron la aplicación de la ley en la frontera, que iba en ascenso desde hacía tiempo, sino que también propiciaron un aumento importante de arrestos, detenciones y deportaciones dentro de Estados Unidos. Ya antes de 1996, las actividades internas para aplicar la ley no habían desempeñado un papel importante en la guerra contra los inmigrantes. Estas actividades aumentaron con posterioridad a niveles no vistos desde las campañas de deportación de la Gran Depresión (Hoffman, 1974; Balderrama, 1995; Kanstroom, 2007). La fusión de la guerra contra el terror con la guerra contra los inmigrantes se indica en la figura 6 , que muestra las deportaciones año a año desde 1965 hasta 2009 (US Department of Homeland Security, 2012). Durante décadas y hasta mediados de los años noventa, la cifra anual de deportaciones no había excedido las 50.000, pero la aprobación de la legislación de 1996 hizo que se traspasara este umbral, de modo que, al final del siglo, las deportaciones ascendían a casi 200.000 por año. Con la autorización del PATRIOT Act a finales de 2001, aumentaron las deportaciones de manera acelerada y casi alcanzaron las 400.000 en 2009. Desde luego que, en los ataques terroristas, no participó ninguna persona de México y ninguno de 
los terroristas entró por México. No hay duda que llegaron a Estados Unidos con visados legales, pero, como muestra con claridad la figura 6 , los mexicanos fueron los más afectados por la campaña de deportaciones lanzada en nombre de la guerra contra el terror, de modo que llegaron a constituir el $72 \%$ de las personas deportadas en 2009.

El efecto desproporcionado de la campaña de deportaciones sobre los inmigrantes latinos se pone de relieve en la figura 7, que muestra la cifra de deportaciones en 2009 por países seleccionados (de nuevo, datos recogidos por la Office of Immigration Statistics). A la izquierda, se observan los cinco orígenes nacionales con más deportaciones, encabezados por México, con 282.666, y seguido a gran distancia por Guatemala, con 29.182; Honduras, con 26.849; El Salvador, con 20.406, y Brasil, con 3.407. En el centro, mostramos las deportaciones del país de origen de los terroristas del 11-S. La cifra más elevada corresponde a Egipto, con únicamente 132, una mínima fracción comparada con la de los mexicanos, y las cifras de deportaciones para Arabia Saudita y los Emiratos Árabes Unidos son aún más insignificantes, 17 y 3, respectivamente. A la derecha, se observan las frecuencias de deportaciones para otros países por lo general ligados al terrorismo, incluyendo Indonesia (352), Pakistán (315), Yemen (48), Irán (42), Siria (31), Irak (31), Afganistán (17), Kuwait (10) y Libia (0). Si tenemos en cuenta todo el conjunto, el 97\% del total de deportaciones en 2009 correspondía a América Latina y el Caribe, y únicamente el

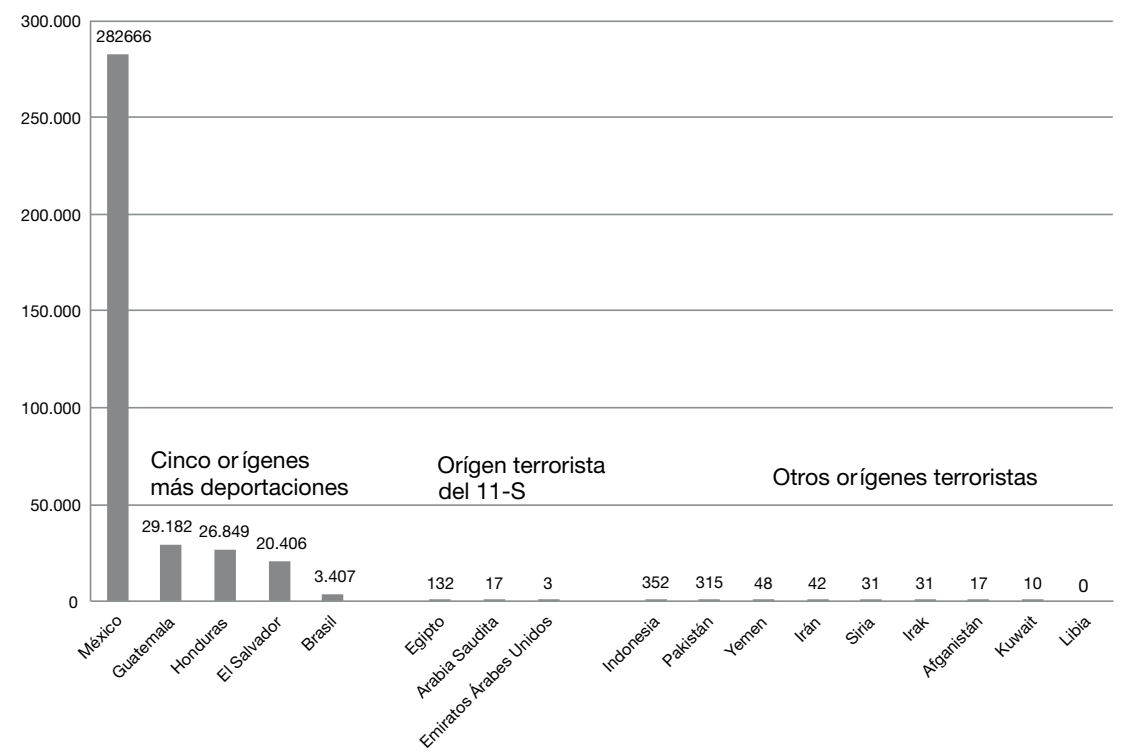

Figura 7. Deportaciones desde Estados Unidos en 2009.

Fuente: Office of Immigration Statistics. US Department of Homeland Security (http://www.dhs.gov/files/ statistics/immigration.shtm). 
3\% del total a otros países. Por lo tanto, terroristas islámicos atacaron Estados Unidos el 11-S, y para mostrar a al-Qaeda nuestra solución a la guerra contra el terror empezamos a deportar a los inmigrantes de América Latina de manera masiva.

La dinámica por la cual se llegó a este resultado se resume en el diagrama de flujo mostrado en la figura 8 , que utiliza una estimación de series temporales de 1965 a 2009 para calcular los efectos de los dos ataques más importantes de los terroristas islámicos sobre el número de deportaciones y, a través de ellos, sobre la reacción conservadora, además del efecto vigente mediante detenciones en la frontera. La información del presupuesto del Servicio de Inmigración y Naturalización, y su agencia sucesora, Immigration and Customs Enforcement, se obtuvo del Homeland Security's Office of Immigration Statistics (US Department of Homeland Security, 2012), complementándolas con otras fuentes. Al indicador del ataque terrorista de 1993, le dimos un valor de 1 de 1993 en adelante y de cero en sentido contrario, mientras que el indicador del ataque terrorista de 2001 fue codificado con un 1 durante 2001-2009 y con un 0 en fechas anteriores.

En este modelo, que cubre totalmente el periodo de 1965 a 2009, continúa el efecto de las detenciones, pero su influencia en la reacción conservadora es ahora mucho más directa $(0,806$ — ver la flecha entre las detenciones y la reacción conservadora-) que indirecta a través del ciclo de retroalimentación, que no llegan, efectivamente, a la unidad $([0,806 \times 0,304 \times-0,187 \times$ $0,886 \times 0,269]+[0,806 \times 0,006 \times 1,143 \times 0,886 \times 0,269]=-0,010)$. Además, el aumento en la cifra de detenciones no está ya conectado con el aumento de deportaciones, con un efecto tamaño de únicamente $-0,036([0,806 \times 0,304$ $\times-0,187 \times 0,886]+[0,806 \times 0,006 \times 1,143 \times 0,886]=-0,036)$. El repunte

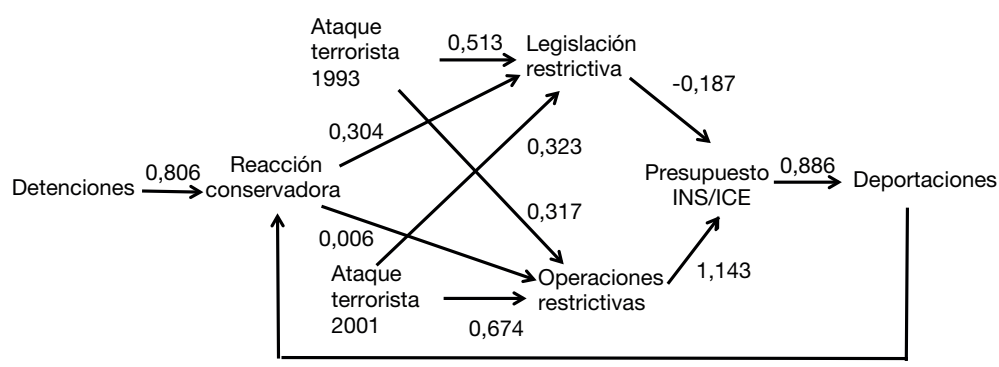

0,269

Efecto de la reacción conservadora Deportaciones: $-0,011$ Reacción Conservadora: $-0,010$
Efecto del ataque terrorista 1993 Efecto del ataque terroristsa 2001 Deportaciones: $\quad 0,236$ Deportaciones: $\quad 0,615$ Reacción Conservadora: $\quad 0,063$ Reacción Conservadora: 0,159

Figura 8. Ciclo de retroalimentación entre deportaciones y medidas internas para aplicar la ley. Fuente: Tabla A1 en MASSEY, Douglas S. y PREN, Karen A. (2012). «Unintended consequences of US Immigration policy: Explaining the post-1965 surge from Latin America», Population and Development Review, 38 (1), 1-29. 
en las detenciones se deriva, principalmente, de los dos ataques terroristas más importantes y la legislación antiterrorista resultante, con los efectos respectivos de $0,236([0,513 \times-0,187 \times 0,886]+[0,317 \times 1,143 \times 0,886]=0,236)$ y 0,615 $([0,323 \times-0,187 \times 0,866]+[0,674 \times 1,143 \times 0,866]=0,615$. Los efectos de retroalimentación de los ataques terroristas, al provocar una reacción en contra de los inmigrantes mediante deportaciones son, también, relativamente modestos, de 0,063, para el ataque de $1993([0,513 \times-0,187 \times 0,886 \times 0,26$ $9]+[0,317 \times 1,143 \times 0,886 \times 0,269]=0,063)$, y de 0,159 , para el ataque de $2001([0,323 \times-0,187 \times 0,866 \times 0,269]+[0,674 \times 1,143 \times 0,866 \times 0,269]=$ 0,159 . Si bien se trata de efectos importantes según los estándares en ciencias sociales, son insignificantes comparados con el efecto total de retroalimentación de 0,692 observado en el modelo de detenciones. El surgimiento de Estados Unidos como una nación de deportaciones (en palabras de Kanstroom, 2007) fue más un resultado de sucesos externos asociados al terrorismo islámico que un ciclo autorrepetitivo que involucró deportaciones, reacción y aplicación de la ley, como fue el caso del ciclo de detenciones.

\section{La extraña carrera de la guerra contra los inmigrantes}

En este trabajo, hemos trazado la carrera paradójica de la guerra actual contra los inmigrantes reconstruyendo, irónicamente, las reformas a los derechos civiles promulgadas en 1965. Estas reformas, que eliminaron el prejuicio (racial) del sistema de inmigración, también eliminaron, inadvertidamente, las rutas legales de ingreso desde México, al colocar restricciones inmediatas a un flujo institucionalizado de cruce de frontera establecido en décadas anteriores bajo el Programa Bracero (1942-1964) y autorizado por la exención de restricciones numéricas de los países del hemisferio occidental bajo los Quota Acts de 1921 y 1924.

El giro de la política de Estados Unidos no cambió la demanda de trabajo de inmigrantes, como tampoco eliminó los lazos establecidos entre los antiguos braceros y los patrones estadounidenses, ni desmanteló las redes sociales surgidas para sostener tales flujos. Sin embargo, con las restricciones en las opciones de entradas legales después de 1965, los flujos migratorios bien establecidos sencillamente continuaron bajo la figura de indocumentados. La inmigración ilegal posterior a 1965 aumentó sostenidamente hasta casi restablecer el volumen de inmigración que prevalecía al final de los años 1950. Más que la cifra de inmigrantes, lo que cambió fue la categoría con la que entraban los mexicanos a Estados Unidos. En términos prácticos, Estados Unidos cambió un sistema migratorio de iure de trabajo temporal apoyado en la circulación legal de braceros y el establecimiento de un modesto número de inmigrantes legales, a un sistema apoyado de facto en la circulación ilegal de trabajadores indocumentados y un sistema más restringido de inmigrantes legales.

A pesar de que esta transformación se concluyó, en gran parte, a finales de la década de 1970, el cambio de legales a ilegales originó consecuencias profundas en la política y en las políticas de Estados Unidos, ya que se convirtió en 
una herramienta de ayuda para que aspirantes políticos y funcionarios ambiciosos del país utilizaran esta inmigración como una nueva y grave amenaza para la nación. Poco había cambiado, exceptuada la categoría de entrada, pero el hecho de que la vasta mayoría de mexicanos entrara ilegalmente significó que los inmigrantes podrían ser incriminados por definición como «criminales» o «infractores», con todas las connotaciones y los atributos negativos vinculados a estas etiquetas. El aumento sostenido de la inmigración ilegal desde 1965 hasta finales de la década de 1970 originó lo que Chávez (2008) ha denominado "la narrativa de la amenaza latina» en los medios de comunicación de Estados Unidos, inmigración de América Latina en general y de México en particular, como una "crisis» en que se utilizaban metáforas amenazantes, tanto bélicas como marinas. Día a día, los inmigrantes latinos se convirtieron en un «maremoto» que amenazaba con «inundar» la sociedad de Estados Unidos, y en «invasores extranjeros» que podrían «abarrotar» y «conquistar» el país. Es más, durante la Guerra Fría, los inmigrantes ilegales se asociaban habitualmente con espías comunistas y, después de emprender la guerra contra el terror, con terroristas islámicos.

La imagen negativa y las alegorías en los medios de comunicación, junto con el aumento del despliegue de los actores políticos en los debates públicos, significaron un buen instrumento para construir la conciencia popular de que la inmigración ilegal era un asunto social y se fomentaron las actitudes en contra de los inmigrantes, reacción ligada íntimamente al enorme aumento del conservadurismo en Estados Unidos. Aumentaban las detenciones y los medios de comunicación hacían alarde de ello; aumentaba la identificación de los estadounidenses como conservadores y, en la medida que crecía su conservadurismo, apoyaban más y más las políticas de exclusión de la inmigración y la vigilancia de la frontera.

Así que el aumento de la inmigración indocumentada después de 1965, respaldado por el objetivo loable de eliminar el racismo del sistema de inmigración de Estados Unidos, originó consecuencias involuntarias al promover un retroceso conservador en contra de la inmigración, porque transformó, inadvertidamente, un flujo legal de migrantes mexicanos bien establecido a uno amparado por la ilegalidad. Si bien el volumen de inmigración ilegal se había estabilizado al final de los años setenta, las detenciones continuaron en ascenso respaldadas por una poderosa dinámica que, a más detenciones, mayor reacción conservadora provocaba, que, a su vez, fomentaba acciones legislativas adicionales y administrativas restrictivas. Estas acciones, por su parte, hicieron aumentar los esfuerzos de aplicación de la ley, a fin de generar aún más detenciones. Esta dinámica condujo al aumento sostenido de la aplicación de la ley y de las detenciones en la frontera durante las décadas de 1980 y 1990, a pesar de que el volumen subyacente de inmigración ilegal había cesado de incrementar.

A pesar de que esta dinámica de retroalimentación quedó bien establecida en los años noventa, la guerra contra los inmigrantes reforzó su avance por procesos exógenos que activaron más acciones legislativas y operaciones buro- 
cráticas, lanzadas como parte de una nueva "guerra contra el terror». Después de los ataques terroristas de 1993 y 1995, el Congreso aprobó de inmediato el Anti-Terrorism and Effective Death Penalty Act en 1996 y, a partir de la siguiente cascada de ataques en 1998, 2000 y 2001, promulgó el USA Patriot Act. Estos proyectos, además de alimentar el ciclo de retroalimentación de detenciones ya establecido, originaron un nuevo ciclo de retroalimentación centrado en las deportaciones y en la aplicación de la ley en el interior del país. La cifra de deportaciones de extranjeros después de 1996 aumentó a niveles sin precedentes, ya que, en la actualidad, asciende a unas 400.000 anuales, y, a pesar de que éstas se ejecutaron en nombre de la guerra contra el terror, la inmensa mayoría de los deportados no son terroristas, sino personas trabajadoras y originarias de América Latina y el Caribe.

La guerra contra los inmigrantes tiene un desarrollo extraño, porque: 1) se originó a partir de reformas beneficiosas que intentaban eliminar el racismo del sistema de inmigración; 2) no aumentó porque entraran más inmigrantes provenientes de México, sino por las condiciones de ilegalidad bajo las cuales fueron obligados a entrar; 3) alcanzaron cifras elevadas sin precedente, no por el aumento del flujo de ilegales, sino por el resultado de un ciclo de detenciones que se repetía una y otra vez, reacción y aplicación de la ley, dinámica que estaba totalmente disociada de la realidad empírica subyacente, y 4) alcanzó su apogeo con una campaña de deportaciones masivas lanzada como parte de la guerra contra el terror, aun cuando los mexicanos no estaban involucrados en los ataques terroristas que impulsaron tal legislación.

No sólo la guerra contra los inmigrantes tuvo un desarrollo extraño en términos de su recorrido político, legislativo y burocrático, sino que comportó también varias consecuencias perversas y paradójicas ${ }^{3}$. El aumento de la aplicación de la ley en la frontera y la escalada de deportaciones no fue la solución a los problemas asociados a la inmigración de indocumentados, sino que, por el contrario, los empeoró en cada instancia y agravó la escala de sus efectos. De modo que la construcción de las medidas para aplicar la ley a lo largo de la frontera entre México y Estados Unidos no detuvo tanto las entradas como la reducción de la migración de retorno una vez que las personas habían cruzado la línea fronteriza, y así aumentó el flujo neto de inmigrantes ilegales y elevó la tasa de asentamientos permanentes, los que, a su vez, desencadenaron un proceso secundario de reunificación familiar (Massey et al., 2002). Es más, como la militarización de la frontera se concentró, en su inicio, en dos de los sectores con más movilidad (El Paso y San Diego), los inmigrantes ilegales se canalizaron predominantemente hacia nuevos lugares de cruce en los años siguientes, a lo largo del desierto de Sonora en la frontera con Arizona (Massey, 2012), lo cual aumentó la tasa de mortalidad entre los inmigrantes (Massey et al., 2002) y desvió los flujos de los destinos tradicionales hacia California por unos nuevos que se dirigían a todo el territorio de Estados Unidos (Massey y Capoferro, 2008; Massey et al., 2009).

3. Estas consecuencias se encuentran bien documentadas en Massey et al., 2002. 
El efecto final de la guerra contra los inmigrantes fue, entonces, convertir lo que había sido un flujo estacional de hombres que iban a trabajar en tres estados en una población asentada de familias en cincuenta estados, ello duplicó la tasa de crecimiento de la población indocumentada y disminuyó la tasa de retorno de la migración durante la década de 1990 hasta el año 2005 (Massey et al., 2009). Finalmente, como el Congreso ha despojado progresivamente de beneficios sociales y derechos civiles tanto a los inmigrantes ilegales como a los inmigrantes legales (Legomsky, 2000; Zolberg, 2006), los residentes extranjeros permanentes han solicitado, en gran número, la naturalización como estrategia de defensa (Massey et al., 2002). Esta estrategia es característica de los mexicanos, quienes, a lo largo de la historia, habían tenido tasas de adquisición de la ciudadanía norteamericana extremadamente bajas. Según la información del Yearbook of Immigration Statistics que publica cada año la Office of Immigration Statistics, del US Department of Homeland Security (2012), las naturalizaciones entre los mexicanos se situaban, de promedio, en unas 26.500 anuales en los trece años anteriores a 1996, mientras que, en los trece años posteriores a esa fecha, la cifra ascendió a 121.400, casi cinco veces más. Este hecho es relevante, porque cada nuevo ciudadano de Estados Unidos adquiere el derecho de patrocinar el ingreso de padres, esposas e hijos menores sin restricción numérica. La cifra de entradas de mexicanos avalada por parientes naturalizados en los años anteriores a 1996 ascendía a unos 34.000, pero, en los años posteriores a esa fecha, aumentó a 93.000 anuales.

Para decirlo sin rodeos, si la intención del Congreso y las diversas administraciones en décadas pasadas fue detener la inmigración ilegal y desincentivar la inmigración legal, fallaron sus esfuerzos y, además, resultó ser una medida contraproducente, porque se generó una población más grande y dispersa geográficamente de inmigrantes ilegales que la que hubiese existido, y aumentó el número de personas candidatas que podían obtener un visado legal de residencia. Esto ha servido únicamente para agravar la reacción conservadora y antiinmigrante elaborada por la política económica de Estados Unidos, gracias a las leyes restrictivas aprobadas y a las operaciones de aplicación de la ley lanzadas a partir de 1965. Sólo puede esperarse que los líderes políticos, el Congreso y la población logren encontrar en algún punto el deseo de romper con ese ciclo destructivo y contraproducente en el cual se encuentran inmersos.

\section{Referencias bibliográficas}

Balderrama, Francisco E. (1995). Decade of Betrayal: Mexican Repatriation in the 1930s. Albuquerque: University of New Mexico Press.

Buchanan, Patrick J. (2006). State of Emergency: The Third World Invasion and Conquest of America. Nueva York: Thomas Dunne Books.

Calavita, Kitty (1992). Inside the State: The Bracero Program, Immigration, and the INS. Nueva York: Routledge.

Chapman, Leonard F. (1976). «Illegal Aliens: Time to Call a Halt!». Reader's Digest, octubre, 188-192. 
CHÁvez, Leo R. (2001). Covering Immigration: Population Images and the Politics of the Nation. Berkeley: University of California Press.

- (2008). The Latino Threat: Constructing Immigrants, Citizens, and the Nation. Stanford, CA: Stanford University Press.

DiCK, Hilary Parsons (2011). "Making Immigrants Illegal in Small-Town USA». Journal of Linguistic Anthropology, 21, E35-E55.

DoBbs, Lou (2006). War on the Middle Class: How the Government, Big Business, and Special Interest Groups Are Waging War on the American Dream and How to Fight Back. Nueva York: Viking.

FISKE, Susan T. (2011). Envy Up, Scorn Down: How Status Divides Us. Nueva York: Russell Sage Foundation.

Flores, Nadia Y.; Vidales, Guadalupe y Plemon, April (2011). "The Latino Cyber-Moral Panic Process in the United States». Information Communication and Society, 14 (4), 568-589.

Hoffman, Abraham (1974). Unwanted Mexican Americans in the Great Depression: Repatriation Pressures, 1929-1939. Tucson: University of Arizona Press.

Huntington, Samuel P. (2004). «The Hispanic challenge». Foreign Policy [en línea], marzo-abril, 1-12. <http://www.foreignpolicy.com/story/cms.php?story_id=2495>.

Kamen, Al (1990). "Central America is no Longer the Central Issue for Americans». Austin American Statesman, octubre, 21.

Kanstroom, Daniel (2007). Deportation Nation: Outsiders in American History. Cambridge, MA: Harvard University Press.

Kohut, Andrew y Suro, Roberto (2006). America's Immigration Quandary: No Consensus on Immigration Problem or Proposed Fixes. Washington, D.C.: Pew Research Center for the People and the Press and Pew Hispanic Center.

LEE, Tiane L., y FISKE, Susan T. (2006). "Not an Outgroup, Not Yet an Ingroup: Immigrants in the Stereotype Content Model». International Journal of Intercultural Relations 30:751-68.

Legomsky, Stephen H. (2000). «Fear and Loathing in Congress and the Courts: Immigration and Judicial Review». Texas Law Review, 78, 1612-20.

LÓPEZ, Mark H.; MORIN, Rich y TAYLOR, Paul (2010). Illegal Immigration Backlash Worries, Divides Latinos [en línea]. Washington, DC: Pew Hispanic Center. <http://pewhispanic.org/files/reports/128.pdf>.

Massey, Douglas S. (1995). «The New Immigration and the Meaning of Ethnicity in the United States». Population and Development Review, 21, 631-52.

- (1999). «International Migration at the Dawn of the Twenty-First Century: The Role of the State». Population and Development Review, 25, 303-23.

- (2007). Categorically Unequal: The American Stratification System. New York: Russell Sage Foundation.

- (2011). «Epilogue: The Past and Future of Mexico-U.S. Migration». En: OverMYER-VelÁZQUeZ, Mark (ed.). Beyond la Frontera: The History of Mexico-U.S. Migration. Nueva York: Oxford University Press, 241-265.

- (2012). "How Arizona Became Ground Zero in the War on Immigrants». En: ChIn, G. Jack y Hessick, Carissa (eds.). Illegals in the Backyard: State and Local Regulation of Immigration Policy. Nueva York: New York University Press.

MASSEY, Douglas S. y CAPOFERro, Chiara (2008). «The Geographic Diversification of U.S. Immigration». En: MASSEY, Douglas S. (ed.). New Faces in New Places: The Changing Geography of American Immigration. Nueva York: Russell Sage Foundation, 25-50. 
Massey, Douglas S.; Durand, Jorge y Malone, Nolan J. (2002). Beyond Smoke and Mirrors: Mexican Immigration in an Age of Economic Integration. Nueva York: Russell Sage Foundation.

Massey, Douglas S.; Durand, Jorge y Pren, Karen A. (2009). «Nuevos escenarios de la migración México-Estados Unidos: Las consecuencias de la guerra antiinmigrante». Papeles de Población, 61, 101-28.

Massey, Douglas S. y Pren, Karen A. (2012). "Origins of the New Latino Underclass». Race and Social Problems, 4, 5-17.

Massey, Douglas S.; Rugh, Jacob S. y Pren, Karen A. (1995). «The Geography of Undocumented Mexican Migration». Mexican Studies/Estudios Mexicanos, 26, 120-52.

Massey, Douglas S. y SÁNCHeZ R., Magaly (2010). Brokered Boundaries: Creating Immigrant Identity in Anti-Immigrant Times. Nueva York: Russell Sage Foundation.

Massey, Douglas S. y Singer, Audrey (1995). «New Estimates of Undocumented Mexican Migration and the Probability of Apprehension». Demography, 32, 203-13.

Meyers, Eytan (2004). International Immigration Policy: A Theoretical and Comparative Analysis. Londres: Palgrave Macmillan.

National Council of State Legislatures (2011). Immigrant Policy Project: 2010 Immigration-Related Bills and Resolutions. Washington, DC: National Council of State Legislatures, 22 de abril de 2009. <http://www.ncsl.org/default.aspx?tabid $=20244>$.

Nevins, Joseph (2001). Operation Gatekeeper: The Rise of the "Illegal Alien" and the Remaking of the U.S.-Mexico Boundary. Nueva York: Routledge.

Ngai, Mae M. (2003). Impossible Subjects: Illegal Aliens and the Making of Modern America. Princeton, NJ: Princeton University Press.

Oficina Federal de Investigaciones de Estados Unidos (2009). «Hate Crime Statistics.» [en línea], Washington, DC: Federal Bureau of Investigation. <http:// www.fbi.gov/ucr/ucr.htm\#hate>

Rosen, Jeffrey (1995). "The War on Immigrants: Why the Courts Can't Save Us». The New Republic [en línea], 30 de enero. <http:/www.tnr.com/article/politics/ the-war-immigrants>.

Rotella, Sebastian (1998). Twilight on the Line: Underworlds and Politics at the U.S.Mexico Border. Nueva York: W. W. Norton.

Santa AnA, Otto (2002). Brown Tide Rising: Metaphors of Latinos in Contemporary American Public Discourse. Austin: University of Texas Press.

Smith, Rogers M. (1997). Civic Ideals: Conflicting Visions of Citizenship in U.S. History. New Haven, CT: Yale University Press.

- (2003). Stories of Peoplehood: The Politics and Morals of Political Membership. Nueva York: Cambridge University Press.

Tichenor, Daniel J. (2002). Dividing Lines: The Politics of Immigration Control in America. Princeton, NJ: Princeton University Press.

Timmer, Ashley S. y Williamson, Jeffrey G. (1998). «Immigration Policy Prior to the 1930s: Labor Markets, Policy Interactions, and Globalization Backlash». Population and Development Review, 24, 739-772.

US DEPARTMENT OF Homeland SECURITY (2012). <http://www.dhs.gov/files/statistics/immigration.shtm>. Office of Immigration Statistics Website.

Zolberg, Aristide R. (2006). A Nation by Design: Immigration Policy in the Fashioning of America. Nueva York: Russell Sage Foundation. 